Superalloys 2012: 12 $^{\text {th }}$ International Symposium on Superalloys

\title{
EXPERIMENTAL DETERMINATION OF TTT DIAGRAM FOR ALLOY 718PLUS®
}

\author{
Dheepa Srinivasan ${ }^{1}$, Leah Underwood Lawless ${ }^{2}$, Eric A. Ott ${ }^{2}$ \\ ${ }^{1}$ GE Energy, GE India Technology Center, EPIP Phase-2, Whitefield Road, Bangalore - 560066, India \\ ${ }^{2}$ GE Aviation, One Neumann Way, Cincinnati OH 45215-1988, USA
}

Keywords: Allvac ${ }^{\circledR} 718$ Plus ${ }^{\circledR}$, TTT curve, CCT curve, $\gamma$ ' precipitates, $\delta$ phase

\begin{abstract}
The phase evolution of Allvac® alloy 718 Plus ${ }^{\circledR}$ has been determined experimentally via construction of time-temperaturetransformation (TTT) and continuous-cooling-transformation (CCT) curves based on identifying the various phases, their sizes and volume fractions along with distributions as they evolved during thermal treatment. The solution temperature range of interand intra-granular $\delta$ phases and of $\gamma^{\prime}$ have been characterized via detailed microstructural investigations. The $\delta$ phase solvus of alloy 718Plus determined by dissolution during isothermal hold for 0.1 hours ranges between $1010-1071{ }^{\circ} \mathrm{C}$, with clear distinctions between solutioning of grain boundary $\delta$ and complete $\delta$ solutioning. The temperature where the intergranular or grain boundary $\delta$ particles dissolve after 0.1 hours in the investigated material is $1015^{\circ} \mathrm{C}$. At this temperature, grain growth occurs owing to a lack of pinning by grain boundary $\delta$ phase particles. However, it is only at $1065^{\circ} \mathrm{C}$, that a complete dissolution of all $\delta$ particles has been observed. The nose of the TTT curve for $\gamma^{\prime}$ occurs at about $843^{\circ} \mathrm{C}$ for start $(25 \%$ transformation) and end of transformation (100\% transformation). The temperature ranges at which precipitation hardening $\left(704-788^{\circ} \mathrm{C}\right)$, coarsening $\left(843^{\circ} \mathrm{C}\right)$ and over aging $\left(898^{\circ} \mathrm{C}\right)$ take place in the alloy have been located by correlating the TTT and the time-temperature-hardness (TTH) curves. This investigation provides a solid basis for practical processing of the alloy, to be used as a candidate material for $700^{\circ} \mathrm{C}$ applications.
\end{abstract}

Allvac and 718Plus are registered trademarks of ATI Properties, Inc.

\section{Introduction}

Alloy 718Plus is based on the well-known and extensively used alloy 718 where half of the $\mathrm{Fe}$ is replaced by $\mathrm{Co}, 1 \% \mathrm{~W}$ is added, the $\mathrm{Al}$ and $\mathrm{Ti}$ levels are increased. The chemistry of 718Plus ${ }^{\circledR}$ was developed by ATI Allvac ${ }^{\circledR}$ [1]. Various efforts [2-6], have contributed to developing these chemistry modifications as well as process enhancements to achieve a temperature enhancement of about $55^{\circ} \mathrm{C}$, while retaining the beneficial workability and weldability attributes of alloy 718 . The advantage of improved temperature capability over alloy 718 and relative ease of processing and welding is expected to offer a reduced cost material option compared to some other Ni base superalloys, such as Waspaloy, Rene' 41 , and alloy 720 , that function up to a working temperature of about $700^{\circ} \mathrm{C}$.

Alloy 718 , is a Ni-Cr-Fe based alloy with $\mathrm{Nb}(4.75-5.5 \mathrm{wt} \%)$ as the major hardening element. The main strengthening phase in this alloy is a metastable $\mathrm{Ni}_{3}(\mathrm{Nb}, \mathrm{Ti}, \mathrm{Al})$-phase, gamma double prime $\left(\gamma^{\prime \prime}\right)$ [7-8]. The equilibrium counterpart in these $\mathrm{Nb}$ rich alloys is an orthorhombic $\mathrm{Ni}_{3} \mathrm{Nb}$ phase, delta $(\delta)$ phase [7-8]. Delta pins grain boundaries which in turn contributes to Hall-
Petch strengthening of the material. In a typical phase sequence in alloy 718 , the coherent strengthening $\gamma^{\prime \prime}$ precipitates transform to incoherent $\delta$ phase and $\gamma^{\prime}$ phase because $\gamma^{\prime \prime}$ becomes thermodynamically unstable at high temperatures. Most other Nibased superalloys are $\gamma^{\prime}\left(\gamma^{\prime}-\mathrm{Ni}_{3} \mathrm{Al}\right)$ strengthened without $\delta$ or $\gamma$ " and have a higher temperature capability than 718 . Alloys with $\gamma^{\prime}$ strengthening, typically have rapid precipitate nucleation and slow growth and coarsening kinetics which promotes high temperature stability at the expense of processing ease. The 718Plus alloy differs from both 718 and other Ni-based alloys in that it combines the strengthening effects of $\delta$ and $\gamma^{\prime}$ precipitates. Both alloys consist of a typical face centered cubic $\gamma$ phase matrix and orthorhombic $\delta$ phase.

A number of studies have been carried out to establish heat treatment approaches, measure alloy capabilities, and characterize typical structure and properties [2-6]; however, only limited assessment of the phase evolution during heat treatment has been performed and reported. In available published reports, TTT diagrams have been generated using thermodynamic calculations with limited experimental validation. Therefore, this study was focused on obtaining a detailed experimental understanding of alloy 718Plus transformation behavior.

\section{Experimental Procedure}

Materials and Heat Treatments

The composition of the alloy 718Plus material used in this study is compared to that of a typical 718 alloy in Table I. The alloy was supplied by ATI Allvac® as a $254 \mathrm{~mm}$ diameter billet and was subsequently ring rolled and fully heat treated. The heat treatment performed was a solution treatment at $982^{\circ} \mathrm{C}$ for 2 hours, followed by oil quenching, and subsequent aging at $787^{\circ} \mathrm{C}$ for $8 \mathrm{~h}$ with a furnace cool to $704^{\circ} \mathrm{C}$, followed by $8 \mathrm{~h}$ hold at $704^{\circ} \mathrm{C}$, before finally being air cooled.

Table I. Measured composition (wt\%) of 718Plus compared to nominal 718 [6]

\begin{tabular}{|c|c|c|c|c|c|c|c|c|}
\hline Alloy* & Cr & Mo & W & Co & Fe & Nb & Ti & Al \\
\hline 718 Plus & 17.87 & 2.68 & 1.12 & 9.2 & 9.59 & 5.55 & 0.83 & 1.39 \\
\hline 718 & 18.1 & 2.9 & - & - & 18 & 5.4 & 1 & 0.45 \\
\hline
\end{tabular}

* Balance Ni

Generally, the following material conditions were used for assessments in this study:

- Fully heat treated (solutioned and two step aged) material for baseline microstructure analysis.

- Re-solutioned samples given several different controlled cooling rates to assess the effect of cooling rate from the solution temperature on gamma prime evolution.

- Fully heat treated material re-solutioned in a gradient furnace over a $871-1093^{\circ} \mathrm{C}$ temperature range for various solutioning times to understand gamma prime 
and delta solvus temperatures. Delta solvus determination was made from the standpoint of phase dissolution

- Resolutioned material aged in a gradient furnace over a $704-899^{\circ} \mathrm{C}$ temperature range for various times to define the aging TTT and TTH behavior.

Bulk Material Characterization

Phase imaging and evaluation was performed using a JEOL ${ }^{\circledR}$ 2011 FASTEM TEM, operated at $200 \mathrm{KV}$. Electron transparent samples were electrolytically thinned from ground $100 \mu \mathrm{m}$ thick discs that were $3 \mathrm{~mm}$ in diameter. The polishing solution for TEM samples comprised methanol and perchloric acid, in the ratio 80:20, and polishing was performed at -45 to $-35^{\circ} \mathrm{C}, 4-5 \mathrm{~V}$ and 25 milli-amps current. Owing to the structural similarities between the matrix (fcc- $\gamma$ ), and the $\gamma^{\prime}$ precipitates, for $\gamma^{\prime}$ sizes as well as fractions, TEM images have been obtained using dark field using superlattice reflections to discern precipitate size and morphologies. Assessment of $\gamma^{\prime}$ volume fractions were made with the assumption of a spherical precipitate morphology, measurements of projected area from TEM micrographs and experiments to determine TEM foil thickness in the regions analyzed. This calculation is believed to be accurate given the $\gamma^{\prime}$ morphology observed. In general, each average reported $\gamma^{\prime}$ size includes 50-60 particle measurements.

Preliminary phase identification was carried out using XRD (Philips, $\mathrm{CuK} \alpha$ ). Grain size as well as delta phase precipitation was monitored using a JSM 640 FESEM on etched samples. Walkers reagent was used to swab etch the metallographically prepared samples to reveal the grain boundaries and the precipitates. In general 30-40 grains and 30-40 delta particles were measured for determination of average sizes. At all the timetemperature combinations, hardness measurements were carried out using a Vickers microhardness tester, at a load of $100 \mathrm{~g}$, on polished surfaces of the aged specimens. An average of 10 hardness readings were calculated for each condition. Hardness measurements were performed at various other locations, and hence temperatures along the gradient bar to map temperatures at which peak hardening occurred. In parallel, independent phase identification was performed by extraction of individual phases per the methods outlined in the next section.

\section{Phase Extraction Analysis}

The phase extraction in this study involved electrochemical separation of carbides, delta particles and the $\gamma^{\prime}$ phase from the matrix, either individually or as a combination of phases. Bulk material samples with a baseline fully heat treated structure were used. Two solutions were prepared in order to preferentially reveal different phases. Solutions were either $4 \% \mathrm{H}_{3} \mathrm{PO}_{4}$ or $4 \%$ $\mathrm{HCl}$ in water. An electrolytic cell was used with each of the solutions to dissolve the matrix phase of the alloy at $\sim 4 \mathrm{~V}$ for $2-4$ hours. The baseline sample was weighed before and after electrolytic dissolution to determine the total weight of sample. The fine solid residue was separated from the solution by multiple centrifuge and decanting steps using deionized water and later methanol. After each centrifuge run, the clear liquid was decanted from the sample and additional deionized water or methanol were added. After removal of all of the electrolyte solution from samples, and performing a final decanting step using methanol, all remaining extract sample material was poured into several preweighed watch glass plates and dried to evaporate the remaining methanol. Dried materials weights were used to determine weight fraction of extract compared to the total weight of the sample which had been dissolved and materials were analyzed by SEM and XRD characterize phase morphology, chemistry and crystal structure.

\section{Results}

\section{Fully heat treated microstructure}

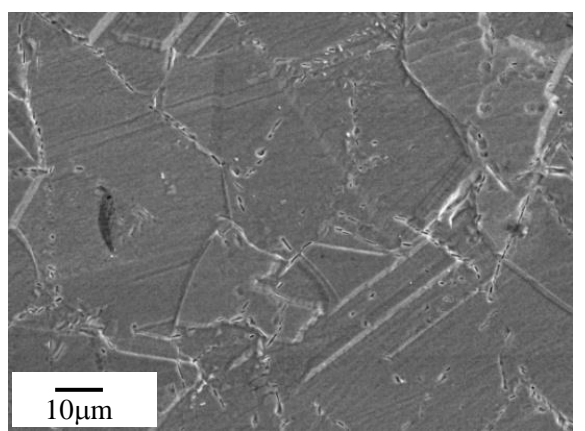

(a)

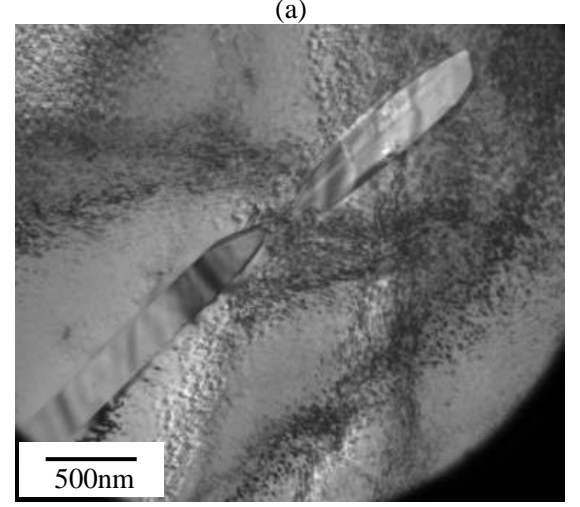

(b)

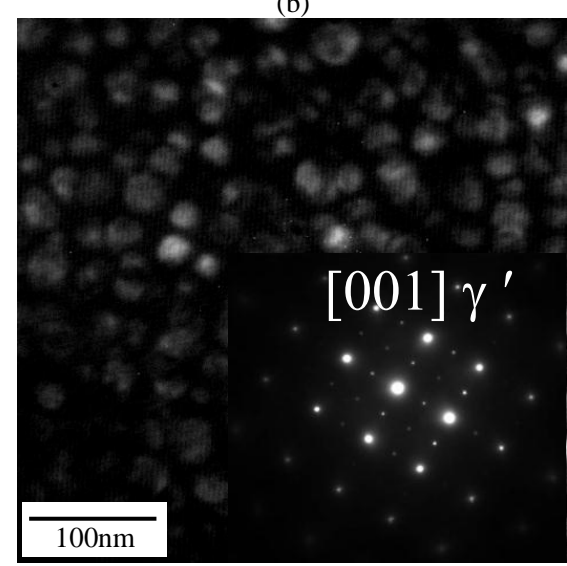

(c)

Figure 1. SEM and TEM micrographs of fully heat treated 718 Plus $\left(982^{\circ} \mathrm{C}\right.$ for $2 \mathrm{~h}$, oil quenching, aging at $787^{\circ} \mathrm{C}$ for $8 \mathrm{~h}$, furnace cool to $704^{\circ} \mathrm{C}, 8 \mathrm{~h}$ hold at $704^{\circ} \mathrm{C}$, air cooled alloy showing (a) overall grain structure, (b) typical $\delta$ phase morphology, and (c) fine scale $\gamma^{\prime}$ structure. 


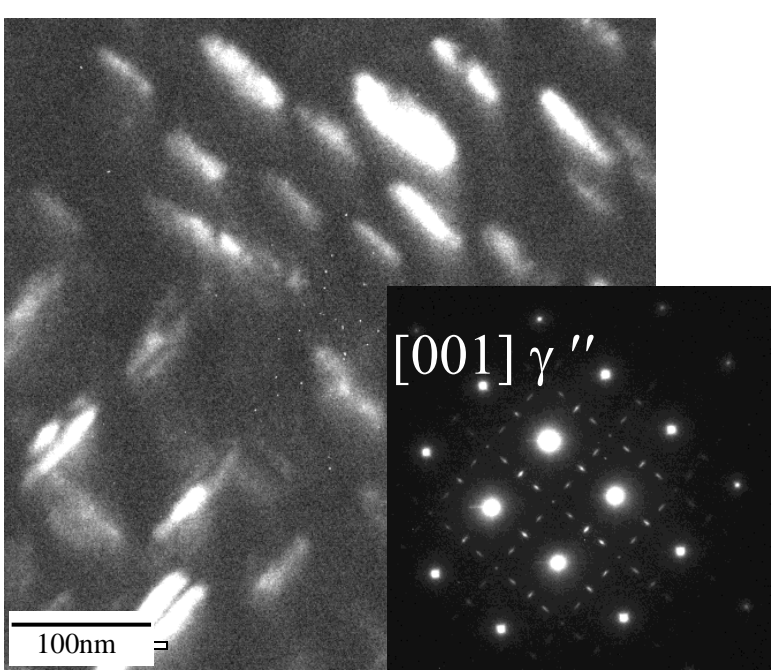

Figure 2. Typical $\gamma^{\prime \prime}$ phase in alloy 718 for comparison.

The fully heat treated (solutioned and two step aged) microstructure of the 718Plus alloy was characterized by SEM and TEM to establish typical phases and morphologies in the structure. The SEM micrograph in Fig. 1(a) shows the overall grain size and delta phase precipitation in the heat treated alloy. The average grain size of the 718Plus material studied was between 30-40 $\mu \mathrm{m}$, corresponding to ASTM 5-7. The $\delta$ precipitates shown in Figure 1(b) in the 718Plus alloy are needlelike, between 3-4 $\mu \mathrm{m}$ in length, with a large fraction present along the grain boundaries. In addition to $\delta$, the $\gamma(\mathrm{Ni}-)$ matrix contains homogeneously nucleated precipitates of $\gamma^{\prime}$ in 718Plus as shown in Fig. 1(c). A comparison between fine scale precipitates in 718 Plus to that of the typical $\gamma^{\prime \prime}$ precipitates in alloy 718 can be seen comparing Figure 1(c) with Figure 2. Insets in Fig. 1c and 2 are selected area diffraction patterns (SADP's) with the beam along [001] orientation, that differentiate one precipitate phase from the other. While $\gamma^{\prime}$ appears spherical, the $\gamma^{\prime \prime}$ precipitates appear as discs with a distinct elliptical morphology, as shown in the dark field images taken using a (100) type reflection and $\left(1 \frac{1}{1} 2\right.$ $0)$ to distinguish between the two types of precipitates. The $\gamma^{\prime}$ phase with an L12 structure is characterized by appearance of superlattice reflections of the type $\{100\}$ and $\{110\}$. The $\gamma^{\prime \prime}$ phase with a DO22 structure has additional superlattice reflections of the type $\left\{1 \frac{1 / 2}{2} 0\right\}$, that give it a unique identity different from the $\gamma^{\prime}$ phase.

Phase identification

Extraction of second phases in the fully heat treated 718Plus alloy was performed in order to more carefully examine their morphology, chemistry and crystal structure in the baseline fully heat treated microstructure. Extractions made using the $\mathrm{HCl}$ solution were expected to consist of $\delta$ and carbide phases while the extract from $\mathrm{H}_{3} \mathrm{PO}_{4}$ solution was expected to consist primarily of $\gamma^{\prime}$. The bulk extracted material weight measurements compared to the original sample weight suggested that the alloy consisted of $0.8 \%$ by weight of $\delta$ and carbides and about $20 \%$ by weight of $\gamma^{\prime}$.

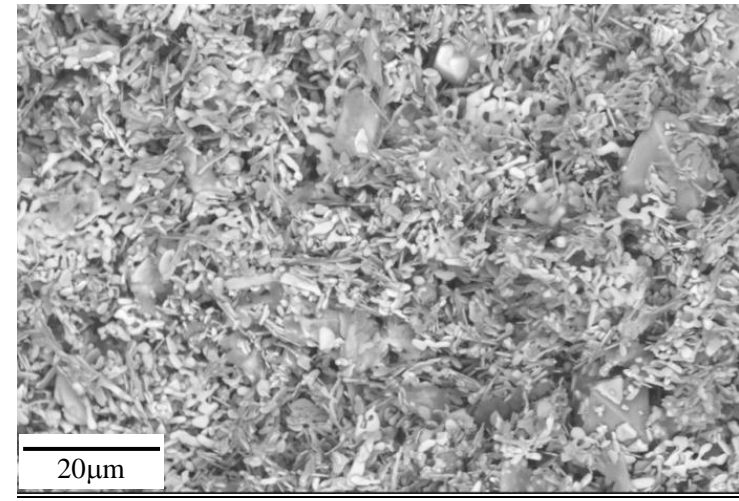

(a)

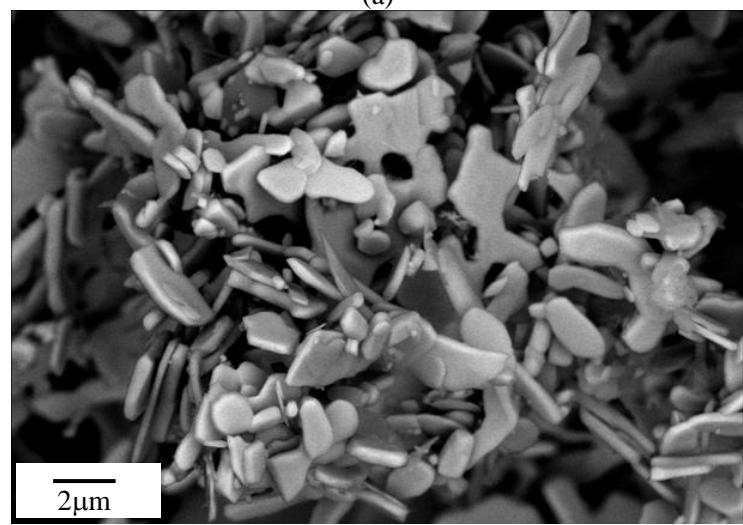

(b)

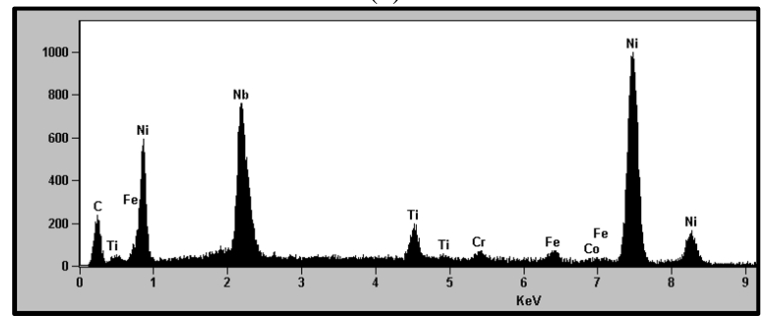

(c)

Figure 3. SEM micrograph of extracted phases from baseline 718Plus fully heat treated sample at (a) low magnification, (b) high magnification, and including a (c) EDX spectrum.

SEM examination of the extracted residues was performed. Figure 3 shows a low magnification and higher magnification view of the phase extracts from the $\mathrm{HCl}$ solution sample targeting $\delta$ and carbide phases along with an SEM EDS chemistry of the bulk extracted material. Figure 4 similarly shows SEM of the $\mathrm{H}_{3} \mathrm{PO}_{4}$ solution extract residue which was targeted to contain only $\gamma^{\prime}$, but based on the micrographs also appears to contain $\delta$. The $\gamma^{\prime}$ is present as very fine particles consistent with the TEM examination of the baseline bulk sample. Semiquantitative chemistry results based on SEM energy dispersive spectroscopy measurements (EDS) are also shown in Table 2.

X-ray diffraction (XRD) of samples including a bulk baseline fully heat treated material, and the extract residue from the $\mathrm{HCl}$ and $\mathrm{H}_{3} \mathrm{PO}_{4}$ solutions was used to assess the phases present in the 718Plus microstructure. Results are shown in Figure 5. The bulk 
alloy XRD pattern confirms that the alloy is predominantly $\gamma$ and $\gamma^{\prime}$ phases. Extractions from the $\mathrm{HCl}$ solution confirm XRD peaks consistent with $\delta$ and MC type carbides. This extraction sample was mainly the orthorhombic $\mathrm{NbNi}_{3}$ phase. The lattice parameters are calculated as $5.1165,4.2206,4.5327$ (technique error estimate of $\sim 0.0005 \AA$ ). The $\mathrm{NbNi}_{3}$ crystallites are somewhat anisotropic as there is texturing seen in the $[0,1,0]$ direction. The abnormal intensity in the $(0,2,0)$ reflection is shown in the pattern. There also appears to be a small amount of NbC-FCC carbide, with lattice parameter of $\sim 4.441 \AA$. Extractions from the $\mathrm{H}_{3} \mathrm{PO}_{4}$ solution confirm peaks consistent with a significant amount of $\gamma^{\prime}$ phase along with a mixture of $\delta$ and carbides similar to that seen in the extracted sample. Other extractions and EDS assessments of carbides also support the presence of NbC type particles in that predominantly $\mathrm{Nb}$ is evident in the EDS.

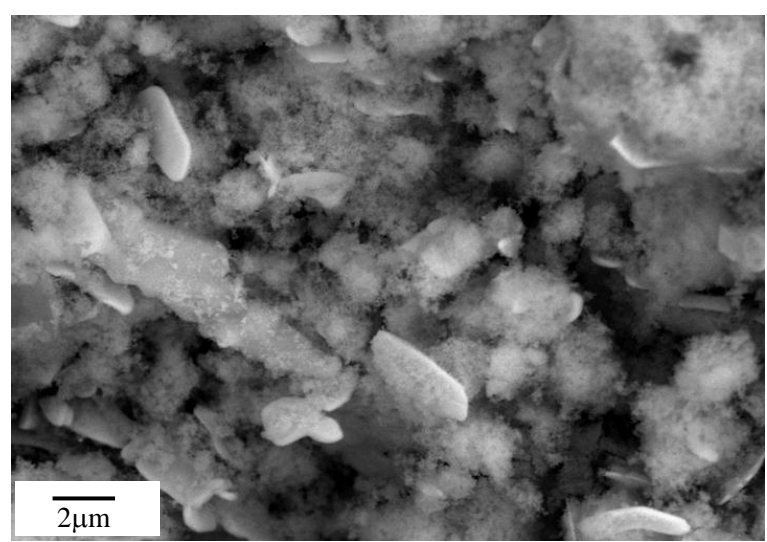

(a)

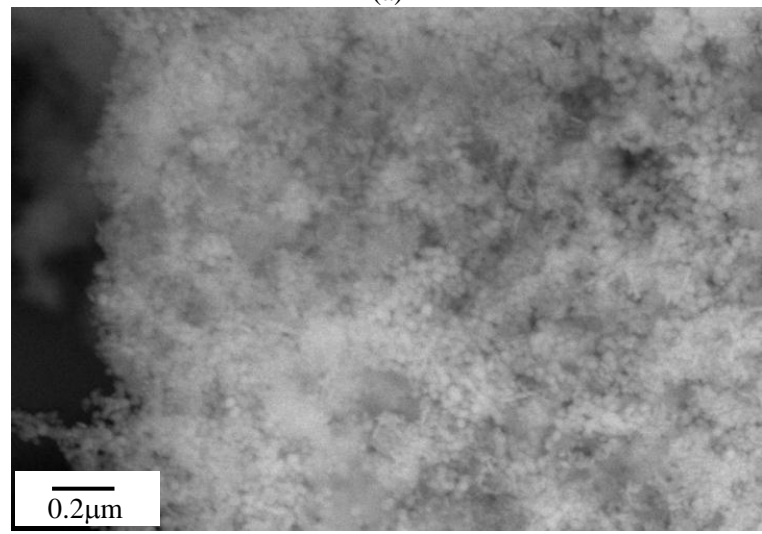

(b)

Figure 4 SEM micrographs of extracted phases from baseline 718Plus fully heat treated sample showing (a) $\gamma^{\prime}$ and some residual $\delta$, and (b) a high magnification view of the very fine $\gamma^{\prime}$.
Table 2. Semiquantitative EDS chemistry of baseline extracts.

\begin{tabular}{|c|c|c|}
\hline Element & $\boldsymbol{\delta}$ and carbides (Atom \%) & $\boldsymbol{\gamma}^{\prime}($ Atom \%) \\
\hline $\mathrm{Al}$ & - & 4.2 \\
\hline $\mathrm{Ti}$ & 5.15 & 4.5 \\
\hline $\mathrm{Cr}$ & 1.62 & 2 \\
\hline $\mathrm{Fe}$ & 1.99 & 3.2 \\
\hline $\mathrm{Co}$ & 0.70 & 2.4 \\
\hline $\mathrm{Ni}$ & 71.85 & 69.3 \\
\hline $\mathrm{Nb}$ & 18.69 & 10.2 \\
\hline
\end{tabular}

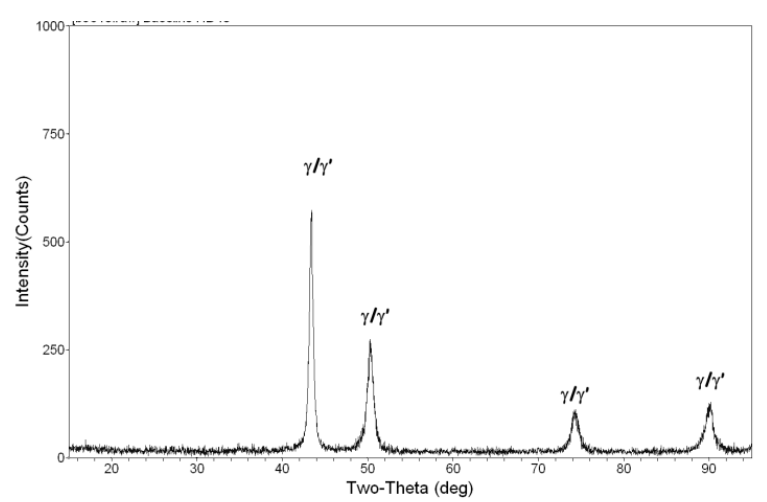

(a)

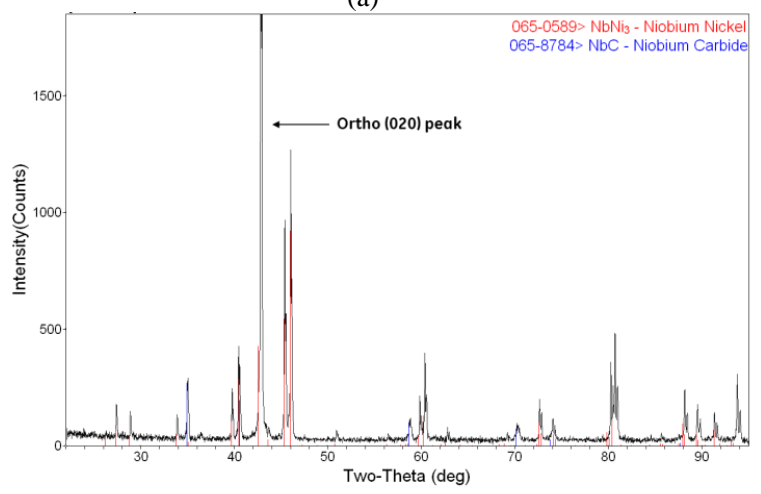

(b)

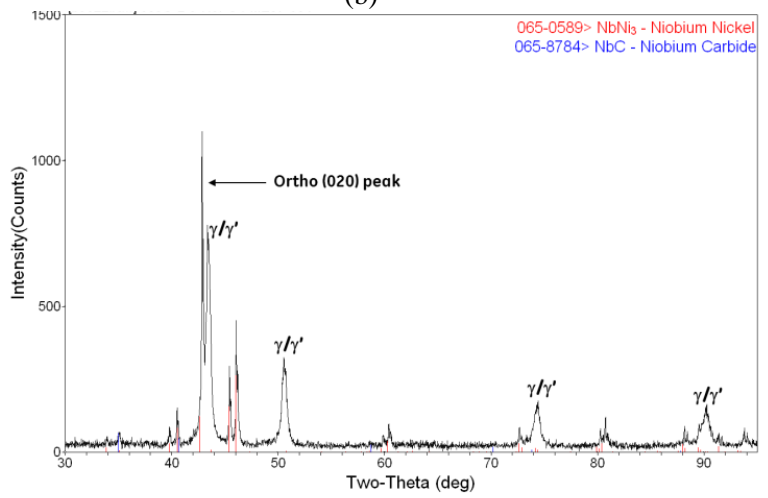

(c)

Figure 5. XRD of (a) bulk 718Plus baseline sample, (b) extracted residue from $\mathrm{HCl}$ solution, and (c) extracted residue from the $\mathrm{H}_{3} \mathrm{PO}_{4}$ solution. 


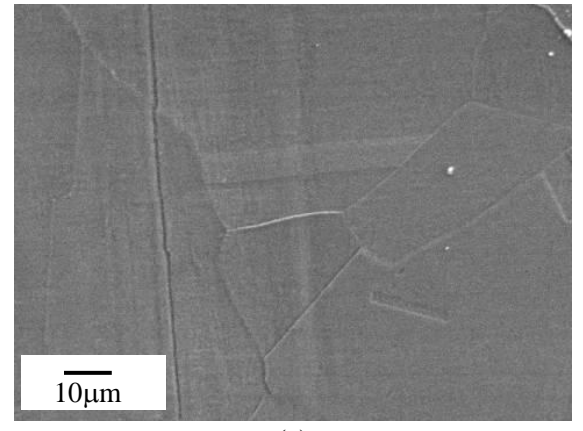

(a)

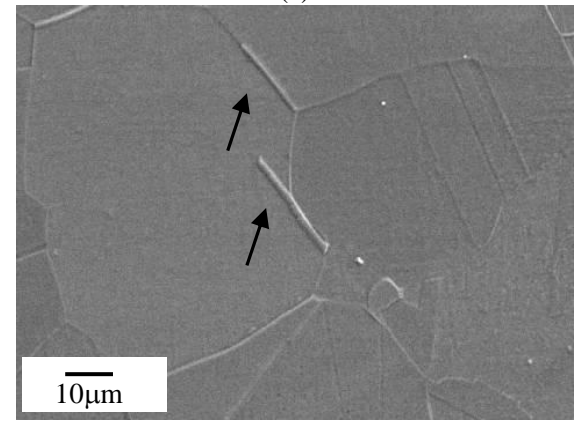

(b)

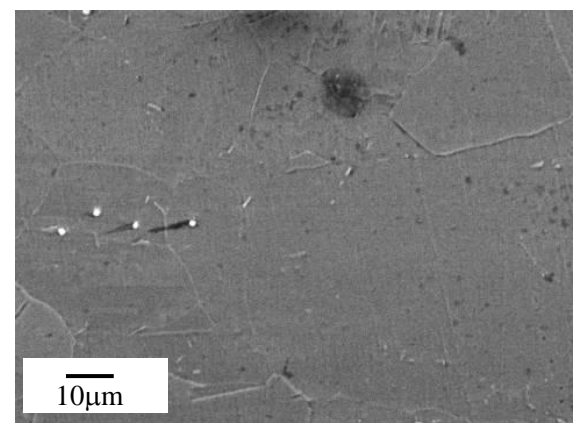

(c)

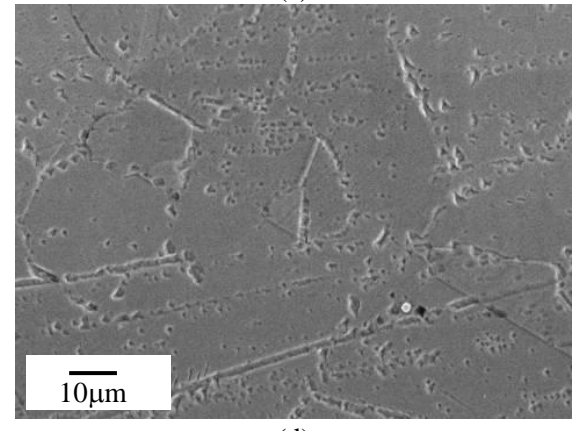

(d)

Figure 6. SEM micrographs after annealing $0.1 \mathrm{~h}$ at several temperatures to investigate $\delta$ dissolution at (a) $1066^{\circ} \mathrm{C}$, (b) $1052^{\circ} \mathrm{C}$, (c) $1016^{\circ} \mathrm{C}$, and (d) $1012^{\circ} \mathrm{C}$. Arrows denote $\delta$ phase.

\section{Delta Phase Solution Temperature}

The solution temperature range of inter- and intra-granular $\delta$ phases and of $\gamma^{\prime}$ were characterized via detailed microstructural investigations. The $\delta$ phase solvus of alloy 718Plus was determined after isothermal hold for 0.1 hours ranges between $954-1093^{\circ} \mathrm{C}$. Selected micrographs at critical temperatures are shown in Figure 6. The temperature where the intergranular or grain boundary $\delta$ particles dissolve in the investigated material is about $1015^{\circ} \mathrm{C}$. At this temperature, grain growth occurs owing to lack of pinning grain boundary $\delta$ phase particles. However, it is only at $1065^{\circ} \mathrm{C}$, that a complete dissolution of all $\delta$ particles has been observed.

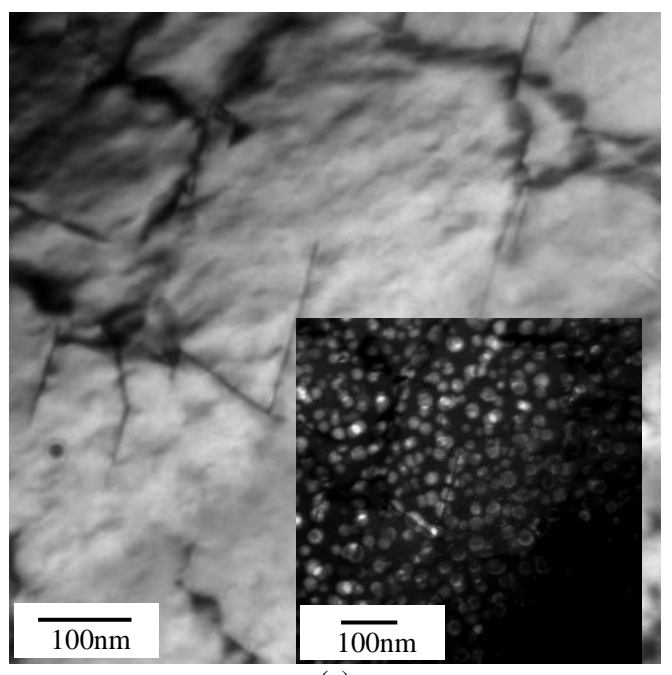

(a)

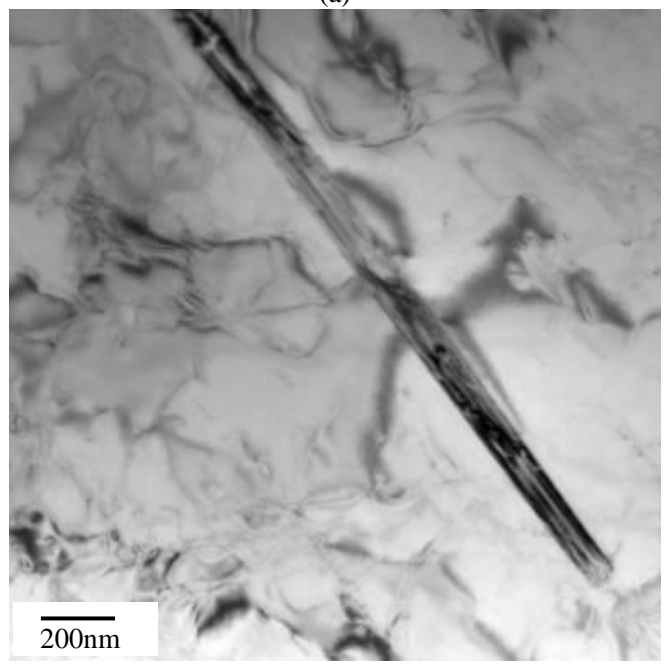

(b)

Figure 7. TEM micrographs showing transition between (a) presence of $\gamma^{\prime}$ phase at $899^{\circ} \mathrm{C}$ for $0.1 \mathrm{~h}$ and (b) absence of $\gamma^{\prime}$ phase due to dissolutioning at $954^{\circ} \mathrm{C}$ for $0.1 \mathrm{~h}$.

\section{Gamma Prime Solution Temperature}

The gamma prime solvus has been assessed by TEM. Analysis of $\gamma^{\prime}$ precipitates was performed between $704^{\circ} \mathrm{C}$ and $982^{\circ} \mathrm{C}$. Precipitates exist at temperatures at and below $899^{\circ} \mathrm{C}$ but not at temperatures at or above $954^{\circ} \mathrm{C}$ as shown in Figure 7. The insert in Fig. 7a shows a dark field image of fine $\gamma^{\prime}$ precipitates in the 
matrix after $0.1 \mathrm{~h}$. The $\gamma^{\prime}$ solvus lies in the $899^{\circ} \mathrm{C}-954^{\circ} \mathrm{C}$ range; finer granularity of assessment was not performed in the current effort. Vickers hardnesses as a function of annealing temperature shown in Figure 8 also support solutioning of the $\gamma^{\prime}$ precipitates in this temperature range.

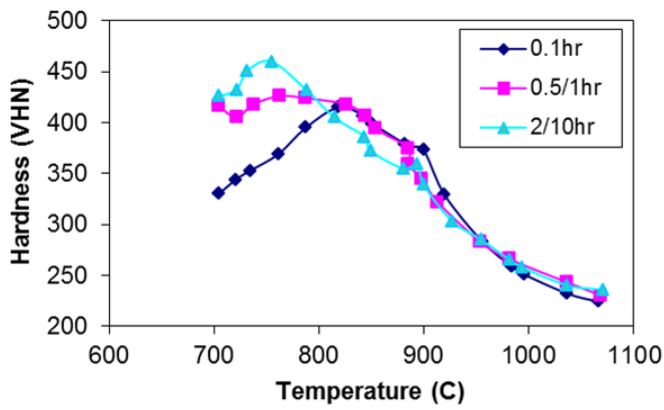

Figure 8. Variation of hardness with temperature for alloy 718 Plus. Note - above $899^{\circ} \mathrm{C}$, the alloy was subject to $0.1,0.5$ and $2 \mathrm{~h}$ dwell times. Between $843-721^{\circ} \mathrm{C}$ the alloy is aged for 0.1 , 1 and $10 \mathrm{~h}$.

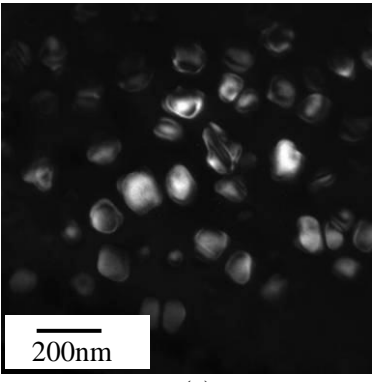

(a)

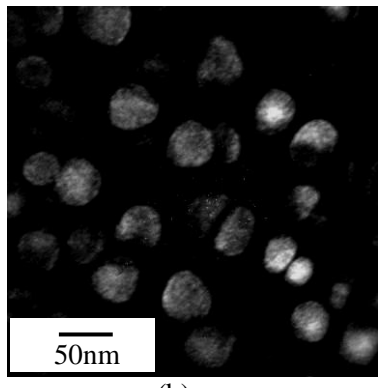

(b)

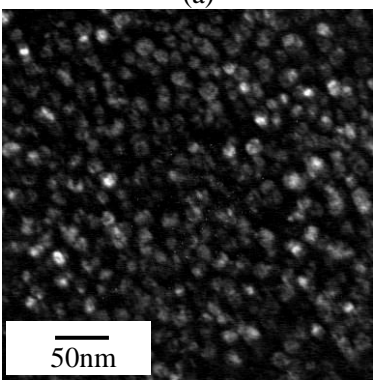

(c)

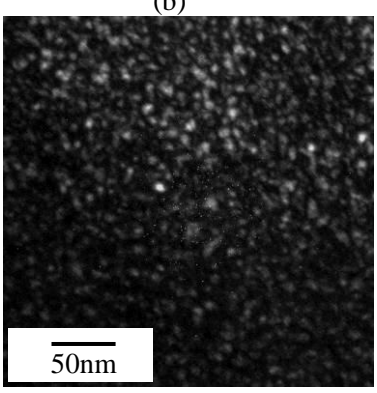

(d)
Figure 9. Dark field TEM images revealing $\gamma^{\prime}$ precipitation as a function of increasing cooling rates of (a) 2.2, (b) 17, (c) 74, and (d) $220 \mathrm{C} / \mathrm{min}$.

\section{Cooling Rate Effects on Phase Precipitation}

Evaluation of the cooling rate effects on precipitation size and volume fraction for the $\gamma^{\prime}$ phase was also performed. The $\gamma^{\prime}$ precipitates display vast differences in both size and volume fraction as a function of cooling rate, as illustrated in the dark field TEM images Figure 9 a-d. Figure 10 shows plots of the $\gamma^{\prime}$ sizes and volume fractions at different cooling rates. It can be seen from Figure 10 that while the $\gamma^{\prime}$ size decreases with increases in the cooling rate, the volume fraction of $\gamma^{\prime}$ reaches a peak value at $17 \mathrm{C}^{\circ} /$ min quench rate. Oil quenching from a $954^{\circ} \mathrm{C}$ solution temperature results in complete suppression of precipitation as shown in the preceding section on $\gamma^{\prime}$ solution temperature. Also, interpolation of $\gamma^{\prime}$ size in Figure 10 suggests that a $\gamma^{\prime}$ size equal to the baseline fully aged material can result from cooling rates of approximately $30^{\circ} \mathrm{C} / \mathrm{min}$. In this condition, however, slightly more than half of the maximum 20 volume percent $\gamma^{\prime}$ has precipitated.

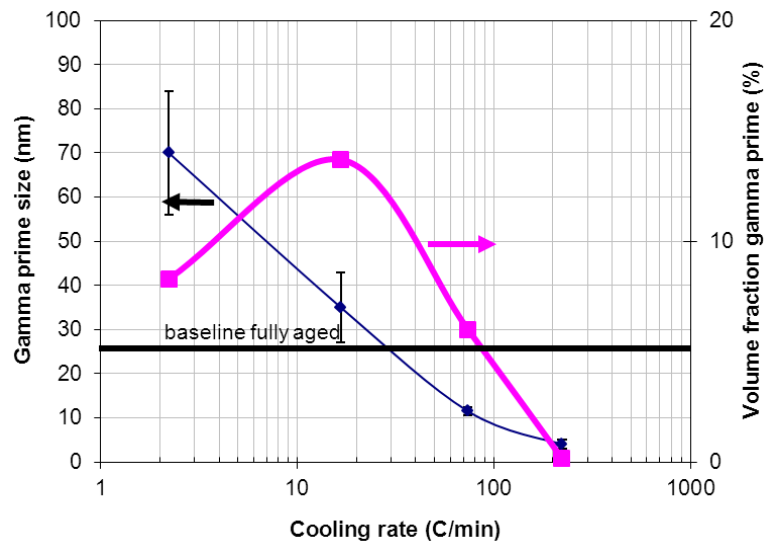

Figure 10. Average $\gamma^{\prime}$ precipitate size and volume fraction of 718Plus as a function of cooling rate from the solution temperature.

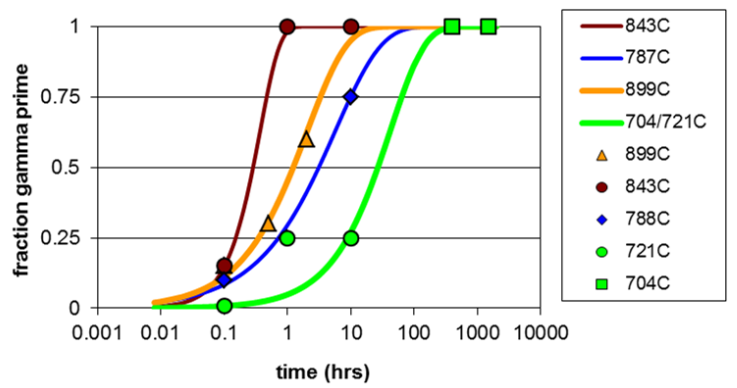

Figure 11. Percentage transformation versus time for different transformation temperatures. 

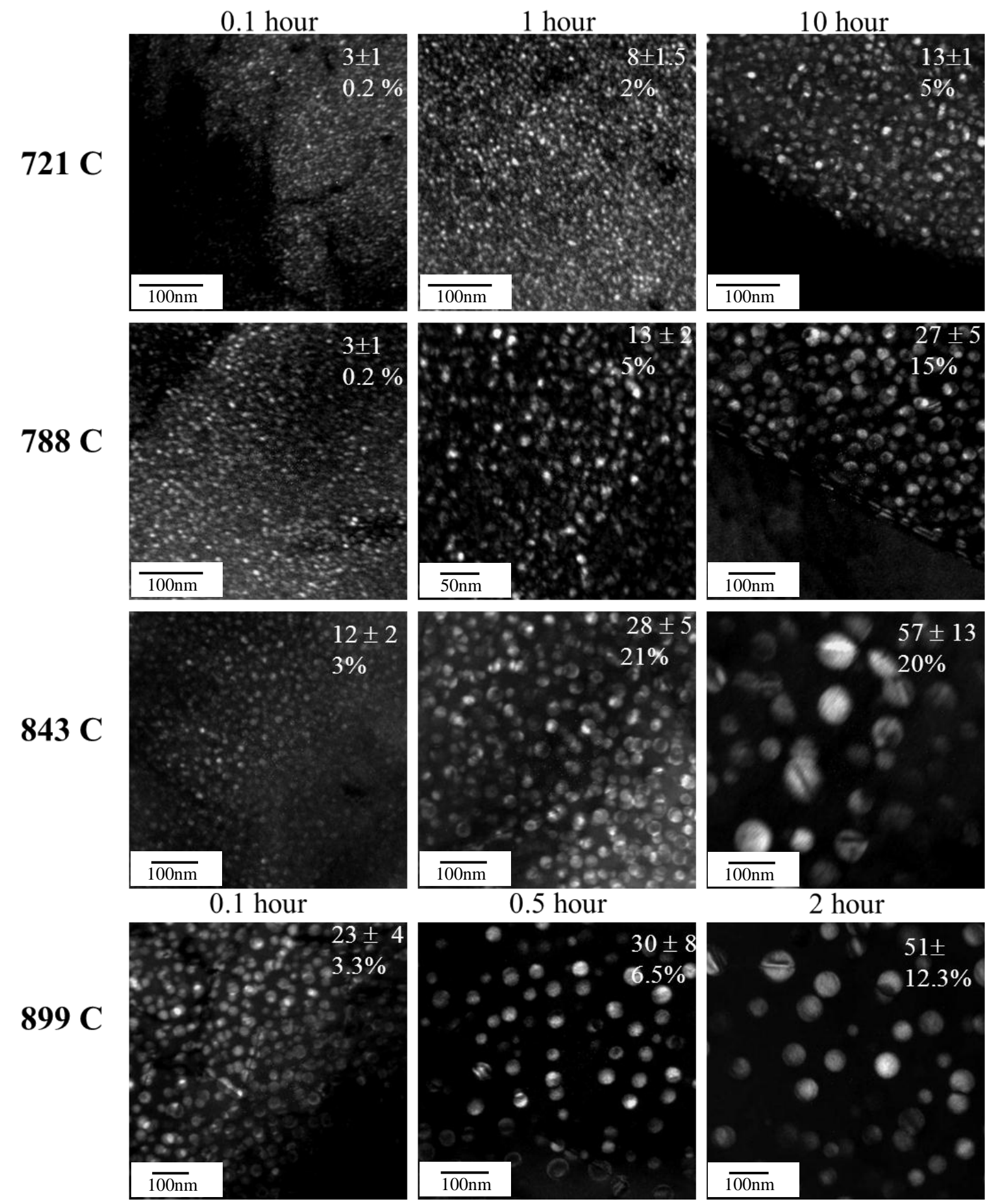

Figure 12. Gamma prime sizes and volume fractions at $721^{\circ} \mathrm{C}, 788^{\circ} \mathrm{C}, 843^{\circ} \mathrm{C}$ and $899^{\circ} \mathrm{C}$, for times of $0.1,1$ and $10 \mathrm{~h}$ between $721^{\circ} \mathrm{C}$ and $843^{\circ} \mathrm{C}$, and $0.1,0.5$ and $2 \mathrm{~h}$ at $899^{\circ} \mathrm{C}$. Legend denotes size in nm and volume fraction (\%). 


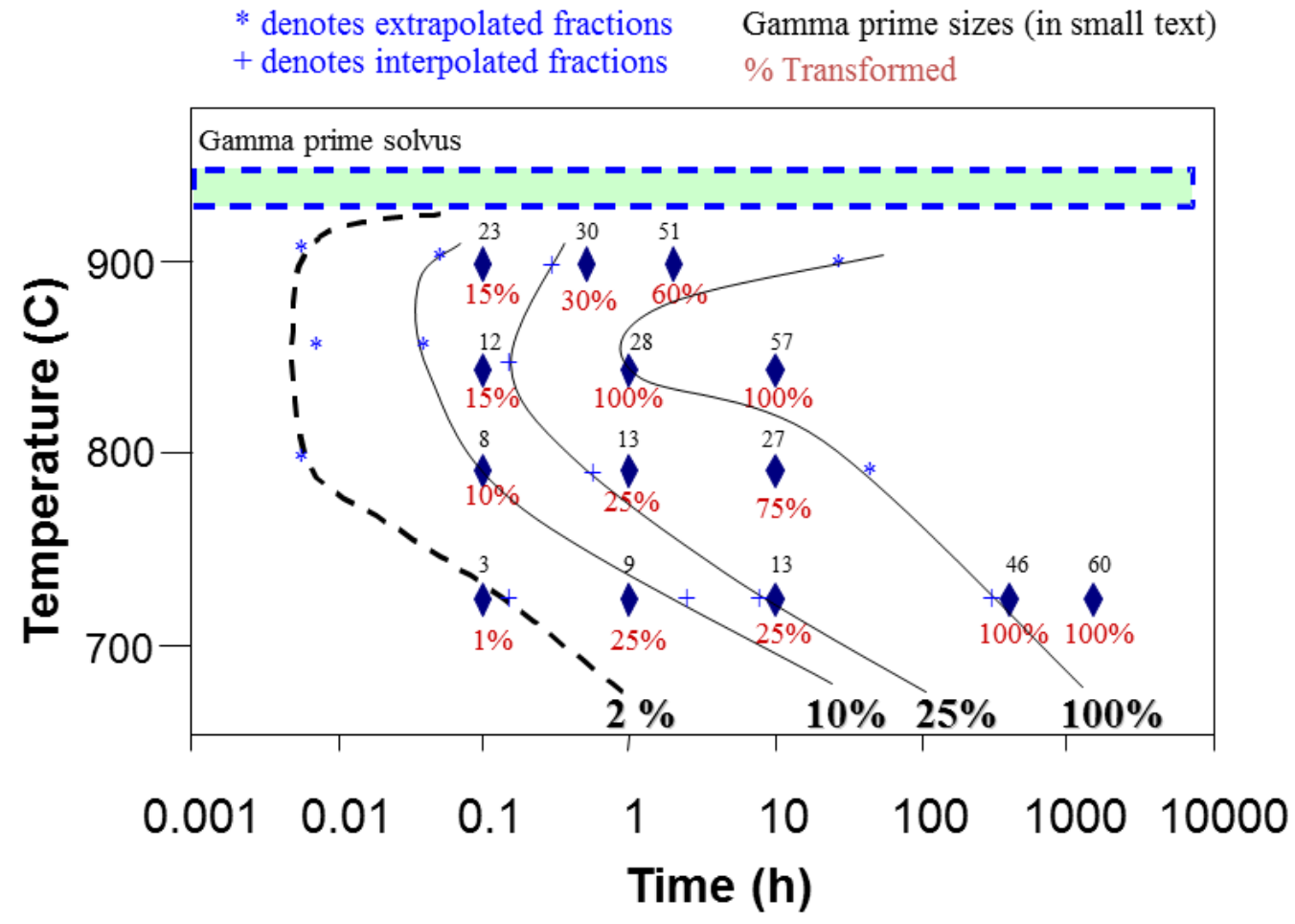

Figure 13. Time-Temperature-Transformation diagram for the gamma prime phase for alloy $718 \mathrm{Plus}$ in the range $704-871{ }^{\circ} \mathrm{C}$ for times 0.5 $-1500 \mathrm{~h}$.

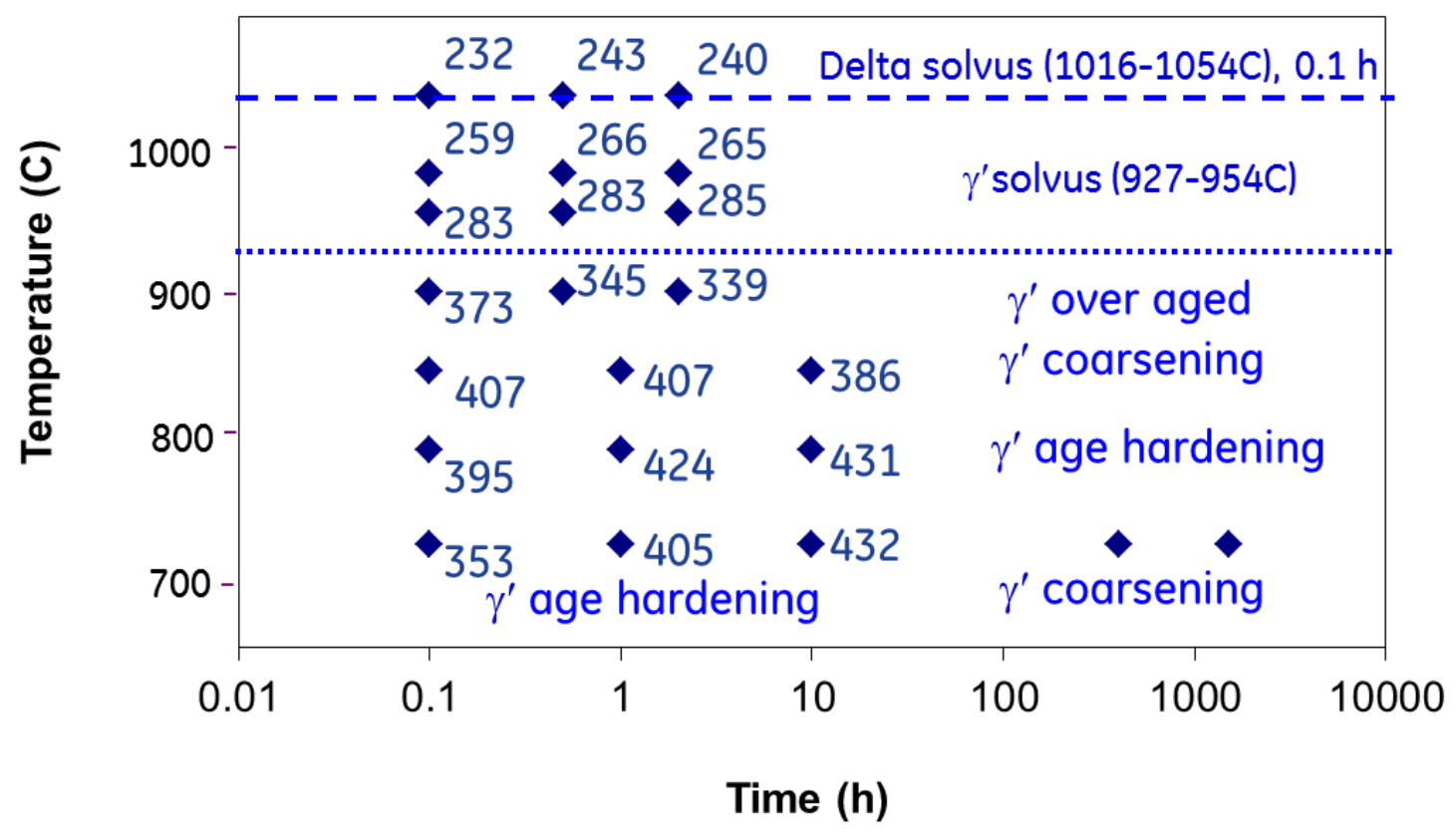

Figure 14. Time-Temperature-Hardness plots of alloy $718 \mathrm{Plus}$ in the range $704-1093^{\circ} \mathrm{C}$ for times $0.5-1500 \mathrm{~h}$. 

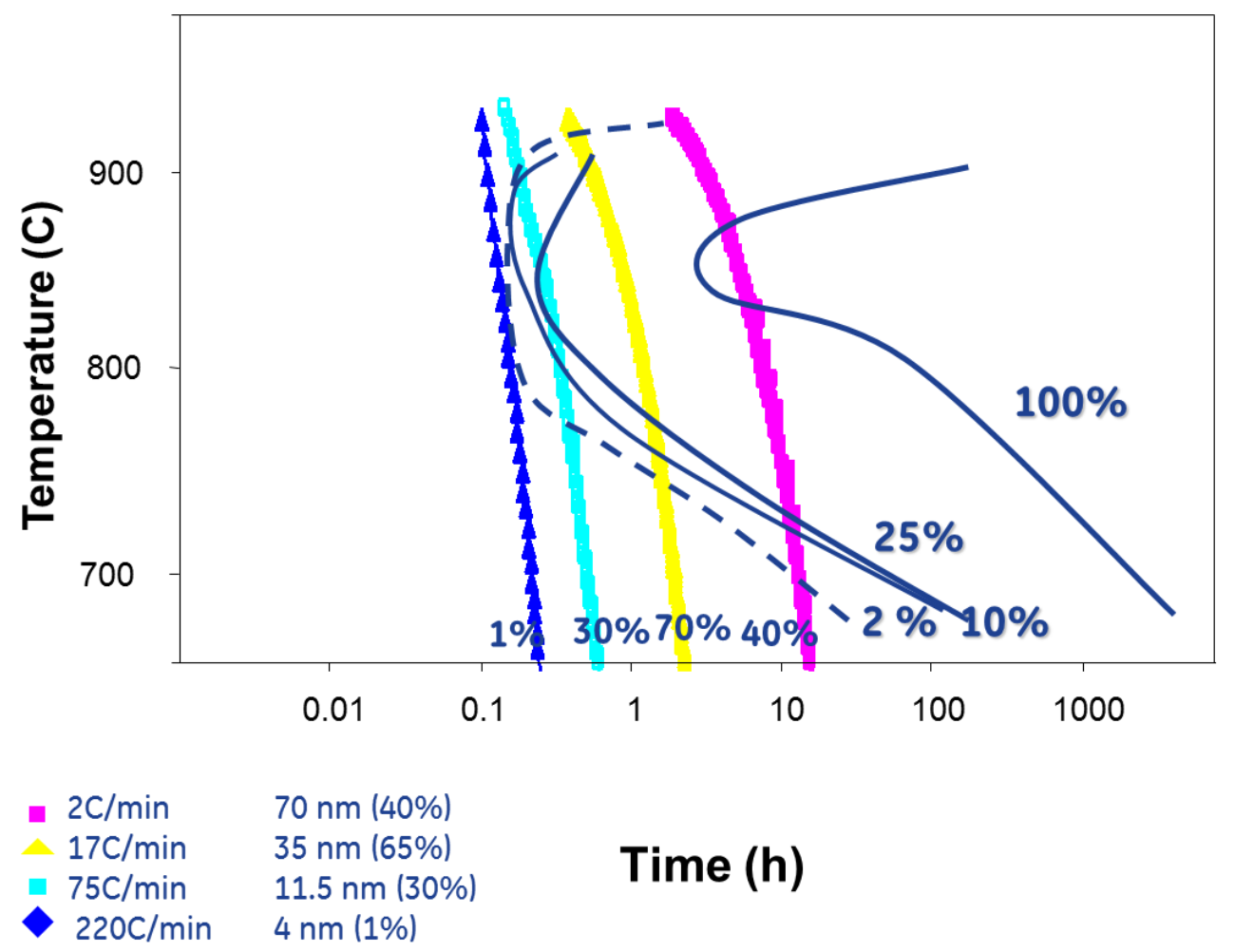

Figure 15. CCT curves for $\gamma^{\prime}$ compared to experimental cooling curves with $\%$ transformed labeled for each.

$\underline{\text { Size and volume fraction of } \gamma^{\prime} \text { versus time and temperature }}$

The isothermal transformation (TTT) diagram was determined by measuring the volume fractions of the $\gamma^{\prime}$ as a function of time at a particular temperature. Temperatures ranging between $704^{\circ} \mathrm{C}$, and $898^{\circ} \mathrm{C}$ with aging times of $0.1,1$ and 10 hours, followed by oil quench were used to examine the evolution of the $\gamma^{\prime}$ phase using TEM. A plot of the volume fraction of $\gamma^{\prime}$ phase as a function of time for the range of temperatures evaluated is given in Figure 11. Figure $12(\mathrm{a}-\mathrm{l})$ is a comprehensive representation of the evolution of $\gamma^{\prime}$ sizes and volume fractions over the range of temperatures and times at which these particles were visible.

\section{Discussion}

\section{Development of TTT Curves}

Time-temperature-transformation (TTT) curves for $\gamma^{\prime}$ precipitation were developed using the data collected on $\gamma^{\prime}$ size and volume fraction. The progress of an isothermal phase transformation can be easily represented by plotting the fraction transformed (Vf) as a function of time and temperature. Figure 13 is a plot of the time temperature transformation, with representative $\gamma^{\prime}$ sizes (in small font) and volume fractions of the transformed product, at each time-temperature location. Subsequently, contours were constructed to develop the TTT diagram. The nose of the TTT curve for $\gamma^{\prime}$, occurs at about $843^{\circ} \mathrm{C}$ for start ( $25 \%$ transformation) and end of transformation (100\% transformation). The temperature ranges at which precipitation hardening $704-788^{\circ} \mathrm{C}$, coarsening $843^{\circ} \mathrm{C}$ and over aging $898^{\circ} \mathrm{C}$ take place in the alloy have been located, by comparing the TTT and the TTH data. Results are shown in Figure 14.

\section{Development of CCT Curves}

The cooling rate curves were used in combination with the TTT curves in order to estimate the CCT behavior. Comparison of results of continuous cooling and isothermal transformation suggest that transformation kinetics on cooling depart somewhat from the isothermal TTT behavior. Due to the limited cooling rate data, an initial CCT diagram was constructed by shifting TTT C-curves to longer or shorter times to be consistent with the cooling rate experimental results as shown in Figure 15. It has been assumed that the temperature at which the nose of the Ccurves occurs is not affected by isothermal vs. continuous cooling.

\section{Conclusions}

1. Characterization of the fully solution and age heat treated Alloy 718Plus material confirmed the presence of $\gamma^{\prime}, \delta$ and MC-type carbides using TEM of bulk samples and electrolytic extractions followed by SEM and XRD analysis.

2. The main strengthening phase in alloy 718Plus has been found to be $\gamma^{\prime}$, throughout the temperature-time ranges used in this study. This is different from alloy 718 which is primarily strengthened by the $\gamma^{\prime \prime}$ phase. Apart from $\gamma^{\prime}$, there is the $\delta$ phase which precipitates both within the grains as well as along the 
grain boundaries. It is the pinning action of these $\delta$ particles that control the grain size in the alloy.

3. The $\gamma^{\prime}$ solvus temperature has been determined to be in the range of $954-899^{\circ} \mathrm{C}$. The inter granular $\delta$ solvus temperature ranges between $1010-1015^{\circ} \mathrm{C}$ for times at temperature of 0.1 hours for situations where delta phase is already present and being dissolved with thermal treatment.

4. The nose of the TTT curve for $\gamma^{\prime}$ precipitation lies at $843^{\circ} \mathrm{C}$ and an experimental TTT diagram was constructed for the $\gamma^{\prime}$ phase for 718Plus.

5. Assessment of the cooling rate behavior of the $\gamma^{\prime}$ phase was characterized. Comparison of continuous cooling transformation kinetics to that of isothermal transformation led to the development of a CCT diagram estimate.

\section{Acknowledgements}

This research was performed under funding from GE Aviation. The authors would like to acknowledge the technical efforts and assistance of T. Vishwanath, and T. Shalini of Materials Research Laboratory, GE India Technology Centre in Bangalore, Ed Raymond and Rob Fecke of GE Aviation, Cincinnati, and Michael Gigliotti and Will Heward of the GE Global Research Center, Niskayuna, NY.

\section{References}

1. W.D. Cao, US patent NO. 6,730,254 B2, 2004.

2. W.D. Cao and R.L. Kennedy, Superalloy 2004, Eds. K.A. Green, T.M. Pollock, H. Harada, T.E. Howson, R.C. Reed, J.J. Schira and S. Walston., TMS, 2004, 91-99.

3. W.D. Cao, Superalloys 718, 625, 706 and derivatives 2005, Eds. E.A. Loria, TMS, 2005, 165-178.

4. X. Xie, G. Wang, J. Dong, C. Xu, W.D. Cao and R. Kennedy, Superalloys 718, 625, 706 and derivatives 2005, Eds. E.A. Loria, TMS, 2005, 179-191.

5. X. Xie, C. Xu, G. Wang, J. Dong, W.D. Cao and R. Kennedy, Superalloys 718, 625, 706 and derivatives 2005, Eds. E.A. Loria, TMS, 2005, 193-202.

6. W.D. Cao and R.L. Kennedy, Acta Metallurgica Sinica, vol. 18, No. 1, pp.39-46, Feb 2005

7. D. F. Paulonis, J.M. Oblak, D.S. Duvall, Trans. ASM., vol. 62, p.611, 1969.

8. M. Sundararaman, P. Mukhopadhyay, S. Banerjee, Met. Trans. A, vol. 19, 1988, p.453. 